\title{
ETHICAL CHALLENGES IN THE USE OF IOT IN EDUCATION: ON THE PATH TO PERSONALIZATION
}

\author{
Cecília Cristina Dos Reis Tomás, António Moreira Teixeira, \\ Laboratory of Distance Education and eLearning (LE@D), Universidade Aberta, Portugal
}

\section{Abstract}

In the research on the ethical challenges related to the Internet of Things (IoT) and the personalisation of the learning process, four key categories have been identified: Security, Privacy, Automation, and Interaction. Based on this framework, using Constructivist Grounded Theory (CGT), we've conducted a study with twenty one actors in the field which have reflected on the advantages, risks and challenges, creating and developing theoretical solutions from technological, pedagogical, and ethical-philosophical perspectives. Coupled with the challenge of interoperability on IoT highways, the educational process generates disadvantages associated with access, use, monitoring and ownership of data, as well as standardization that falls under "profiling" rather than personalization. This leads to problems like exclusion, redundancy of the human being in education through its homogenization and determinism that leads to a loss of sense of freedom, control and choice. The consequence is surveillance associated with corporativism and the loss of the notion of the Common Good in general and in the education in particular. In this paper we discuss how IoT, algorithms and Artificial Intelligence (AI) linked to automation falls within the profiling; and whether more artisanal solutions linked to human language, communication and the relationship that enhance collaboration among multitudes, lead to a stigmeric learning enhancing a personalization of proximity. In this way we are invited to think of a symbiosis between the human being and the machine without the threat of its control, but with the openness and access in education as advantages, the expansion of interaction and communication enhanced by automated processes in pursuit of personalization, distinguishing the cost from the value of data, the value of collective data from the value of personal data among other challenges. In the paper we suggest the idea of a new social contract, whose ethical dimension necessarily rests on the value of the Common Good associated with justice, equity, equality and inclusion. 
Keywords: Ethics, Education, Personalization, Security, Privacy, Automation and Interaction.

\section{What we mean by the Internet of Things}

The Internet of Things is a physical substrate designed to transform all things into intelligent entities by removing them from the amorphous and passive dimension which naturally constitutes them. Through the interactivity allowed by IoT, it will be possible to say that the thing or object itself is, through the internet and its protocols, capable of interconnecting, creating "intelligence", being a Smart Thing. The (artificial) intelligence of each particular thing will certainly depend of its definitions, which gives it a specific personality in the digital world. An object whose definition is to monitor a person, use the data that collect learning with the person to whom it is intended or to whom it belongs, serving the purpose of the interaction between the machine and the human being.

The addressability in the immaterial world of a physical object, is capable of giving each object a virtual identity that allows it to operate in different spaces and to interconnect and learn from others similar to it (interoperability) due to its semantic dimension. With the use of digital databases (Big Data) and the interoperability of these same data, objects (Smart Objects / Smart Things) become, for the human being, an embedded intelligence (an extension of the human body or the increment of a capacity, for example).Since each object is virtually addressable, interoperability gives each object the ability to connect to different other objects making it ubiquitous.

Consequently, "the Internet of Things allows people and things to be connected Anytime, Anyplace, with Anything and Anyone, ideally using Any path/network and Any service."(Perera et al., 2013). Leaving the uniformity and the unidirectionality, the instruments that people use began to have different uses in relation to the initial ones and the human being step into the register of the intermediated connection. In addition to the connection, the IoT allows interconnection and interoperability between data. This is the small (but giant) step that technology lacked so that its use would become a challenge.

\section{Personalization}

\section{The idea of personalization}

Understood both as a characteristic that can be applied to objects that are interconnect in the network from the physical substrate that the IoT provides to them, as well as the probable promise of adaptation to the individual characteristics of each entity that uses these same objects now removed from obscurity, the personalization brings enormous advantages, but also profound risks whose identification, reflection and ethical re-dimensioning may distance dystopias. IoT is a network of relationships of objects that 
are no longer simple objects but also become subjects with information and with the ability to cross data among themselves about subjects who are people (and who come to be seen as objects).

Personalization in the field of objects, is the possibility that each of the objects (produced in series) has its own identity that makes it different from all others, capable of control, obtain, give and even manipulate data (data are behaviours, are people's life) about other objects (capable of representing subjects - people) and about other subjects (that are, effectively, people). The promise of personalization capable of ensuring that each subject corresponds to their needs is real and is possible. There are several areas that are already moving in this direction: from agriculture to industry, from commerce to medicine to wellness centres, from smart watch to smart cloth, from smart cities to smart cars, from museums to libraries and so many other goods and services.

\section{Personalization in Education: technological, pedagogical and ethical aspects}

From 2013 until 2020, the idea of personalization gained increasingly more attention as it went through different conceptions and relations. This evolution started with Buchem and Pérez-Sanagustín who related the concepts of Smart Cities, Personal Learning Environments (PLE) and Smart Citizens (Buchem \& Pérez-Sanagustín, 2013); The K12 NMC Report refers to Learning Analytics (LA) crossed with Big Data in search of personalization (Johnson et al., 2013); The Future of IoTs in Education refers to an inclusive education of children and young people with neurodiversity talking about the access to resources globally (Advanced MP Technology Inc., 2013).The following year saw important advances in the concept of personalization, due to the combination of technologies such as Bring Your Own Device (BYOD), LA, Wearable Technology (WT) and IoT (Johnson et al., 2014).

In 2015 the notion of ubiquitous and integrated learning in the circumstances that the individual goes through, appears for the first time, referring to Hypersituating as "(...) the ability to amplify knowledge based on the user's location. In other words, learners that carry connected devices with them can benefit from a host of interdisciplinary information that is pushed to them from their surroundings. For instance, a learner exploring a city with a rich historical past can explore their environment through an architectural, political, or biological lens, depending on how the surroundings are equipped. IoT can also create an environment where learners are informed by crowd sourced contributions and observations from the community via networked objects." (Johnson et al., 2015). In this year there are also examples related to neurosensors capable of measuring students' brain waves while they learn, allowing teacher intervention in cases of greatest need (Meyers, 2015). 
Mutating again in the following year, the term evolved to the new concept of Wearable Technology (Adams Becker et al., 2016; Freeman et al., 2016), with automation starting to gain ground. It is also at this time that Robotics, AI and Machine Learning begin to be noticed.

But in 2017, the term focused on the generation of data from the students' devices and at the same time it refers to the ethical implications that this data collection can have in relation to security, transparency and privacy (Adams Becker et al., 2017).

The 2018 Horizon Report does not mention IoT, but identifies analytical technologies as an important step towards customization, namely adaptive learning and AI - as an extractive technology (Adams Becker et al., 2018).In 2019, however, the trends continue. The associated ethical issues are mentioned. It still refers to blockchain as a distributed technology, but with a very long time of adoption when it comes to education. (Alexander et al., 2019)

Finally, in 2020 there is no mention to the IoT. Nevertheless, ethical issues begin to emerge (Brown et al., 2020) and are essentially the questions inherent to privacy those that gain ground.

\section{Ethical Challenges on the Internet of Things}

The use of Constructivist Grounded Theory made it possible to build a framework based on the different data presented. The information that preceded this point resulted from theoretical research carried out from different places of information, including the reference literature; the information that follows this point is in accordance with the data collected from twenty-one synchronous interviews.

\section{Security}

The vulnerability of the infrastructures is the first of the challenges because it can be intentionally exploited leading to phenomena of people exchange, hacking, piracy, badness or errors not only of the devices but also of the information network (sensitive information) that represents people and that circulates with a very high level of exposure.

Therefore, security is not only related to the data that represent people, but of the people themselves that can be manipulated from the outside. In an immersive environment whose complexity arises from the connection between AI technologies and IoT technologies, the monitoring of students in real time generates a set of personal, sensitive data, putting at risk the person's physical and personal security, since the data coming from images can be manipulated or stolen. 


\section{Privacy}

Privacy exists only if there is personal data and the data is only valuable because it is private, personal and intimate (privacy - personalization). Without any costs, it is necessary to realize that people are the product for companies.

In education, how much students want to expose about themselves is related to privacy (it concerns to each person's option), but security concerns the fact that what, for example, students do not want to show, is safe. Besides that the issues of privacy intersect with those of personalization since the tendency of AI will be to connect people to paths, with no possibility of being selective in their privacy.

It is also important to differentiate between collective data (Big Data) and personal data (sensitive). The value of the data and the privacy of the data must coexist peacefully. There is data with personal value and there is data with collective value, although sometimes the borders are not well defined. The information belongs to the person and, therefore, society should give due value to that information (not to be usurped, stolen, sold as belonging to other people, companies or corporations) for the collective good that it can generate - the rarer and scarcer it is information, the more value it has.

\section{Automation}

With the help of automation it is possible to reach the individual, find the students' potential, help the student in his learning path (what he has to do, as well as his progress). To give an understanding of the struggles that students have when they have a problem or the good things they are doing, while education is massified, the teacher is better aware of who and where he has to help.

The central point is the agency (having control over operations), with an emphasis on choices and decisions. Sometimes control escapes to the human being, so it's important not to leave human freedom tied to recurrence schemes, otherwise, freedom, choice and decision are conditioned, not to say even determined. For example, BCI devices are potential objects of personalization (creation or extension of capabilities), but the intrusion of rationality when used, for example to evaluate decision making, is a risk.

\section{Interaction}

What changes is the way of interacting with the use of analytical models to assist the teacher, whether in the assessment, re-evaluation or adjustment of the student's curriculum plan. With the introduction of AI and its muscular use, data surveillance can completely change the interaction between all, becoming deterministic the educational process. 
In view of a personalized education model in which the student's profile is the core of the educational process, profiling determines the interactive process of teaching and learning, blocking the essence of education and the question that relates automation with interaction leading to the question the educational process to determinism.

\section{Thinking about solutions}

Based on the interviewees' words, several possibilities were found to consider solutions in relation to the ethical challenges posed by the categories identified above. The following is a list of ideas that enhance the finding of solutions:

- It's important to think about security issues a priori, which implies the creation of technology by multidisciplinary teams at the level of design (diversity of people, experiences, trends ...);

- Make a cultural programming of the intelligent algorithm to include ethical, moral and legal mechanisms, starting with limiters (the notion of safety) which leads to the notion of cyber social contract;

- Having distributed tools as blockchain;

- Anonymizing people to ensure that who accesses to the content will have to be who is authorized, giving good use to what they access (but it will be ethical for only a few to access to some resources?);

- Raising awareness of the definition of policies related to the use of IoT which will imply:

- create a frame of reference and raise awareness of the responsibility for security definitions;

- each institution should have a code of conduct for good practices leading to selfregulation by

- the institution itself;

- scrutinize the conduct of companies and institutions so that there is transparency in institutional relations - it is important to know with whom it speaks.

- ensure the level of reliability of the systems, since it is important to ensure that the systems are available, but only those who should have access to them;

- $\quad$ it is necessary to beware about issues related to the monitoring and the use of data: the data should only be used for the purpose that it serves, and should be destroyed when it is no longer in use.

- it is also to beware about intellectual property issues.

- It's important to teach people how to safeguard their accounts and profiles. 
- $\quad$ Make IoT devices secure:

- $\quad$ restrict its use from the outside;

- create trusting relationships between users and the institution;

- making people aware of the dangers because we depend on machines and programs that we do not understand, which shows the need of digital literacy associated with critical thinking;

- guarantee identity in a relationship between sender, receiver and channel (machines or human beings); guarantee the identity of the content as well as the absence of interference (natural or from the intervention of third parties) because the quality of the information is linked to its veracity (being from a reliable source), correctness (accuracy), usefulness and objectivity (and not to selection of partial information). In education, these references are central.

\section{On the path to Personalization in Education}

Privacy and Interaction are the categories that challenge us as people; Security and Automation are much more linked to technological and institutional issues.

According to the different perspectives of the interviewees in education there are at least two paths: the first one is the IoT way, which means a path of automation, algorithms and AI (based on collected data). With it will be able to address things to types of people creating stereotyped profiles at the risk of homogenization. This is not personalization; is profiling. The other is the Internet of People anchored in large-scale collaboration and linked to human language (which is on the side of communication and relationship) that enhances collaboration between crowds whose paradigm originates from the collaborative construction at the image of Wikipedia. This is stigmergic learning with the use of IoT technologies will allow an Internet of Everything (IoE) anchored in the notion of the Common Good.

In a path whose algorithms and $\mathrm{AI}$ are disconnected from people, notions such as: surveillance capitalism (based on totalitarian governance decisions or peripheral to the common good); determinism (inherent to the educational process); profiling (which is born based on standards of profiles). They lead to the loss of the human factor in education, the risk of losing the sense of freedom as well as human agency, control and choice. A society and an educational system whose foundation put aside the improvement, are condemned to be dominated either by a totalitarian government, or by corporations, companies and institutions whose race to AIs is based on an ethics of good intentions, but it will generate harmful consequences if it does not contain values linked to the Common Good, justice, equity and inclusion, which means an ethics of care. In this sense it's important: to create a new social contract based on the idea of technological safety (a 
limiter of automatisms in terms of security and privacy) and based on the value of the data (different from the cost); distinguish data with collective value and data with personal value; accomplish the symbiosis between human being and machine, in the clear human agency; attend to the scrutiny of conduct codes of institutions and companies and the good institutional practices; attend to an ethical education based on meta values capable of creating multidisciplinary teams (because the technological design must be universal) and people and citizens whose vision is not limited to the specialty of what is the object of study, but that are capable of shared responsibilities and fair and equitable users of common sense.

The construction of a collective intelligence shared and co-built with an Internet of Everything and with the help of different IAs (external and / or built-in), whose functionality is to solve problems (relieve the effort in certain tasks, namely uncomfortable and repetitive, increase or expand capabilities or even increase deficient capabilities) and whose real communication is between and with people, will allow the growth of stigmergic learning and more evolved societies from the human point of view (the humanity point of view). This is possible by the replacement of technology essence in itself through education and by the understanding that its repercussions are too wide and technology couldn't be seen or used as neutral; are essential for the replacement of humanity in people, at the same time that it will imply the symbiosis between them (which seems like an antagonism, but it is not, in fact). This will certainly bring about a new epistemological vision based on complexity and diversity, which brings ethical challenges that have not yet been explored.

\section{Conclusions and future research}

In this paper we've explored a number of questions whose answer, related to the construction of a more just, egalitarian and equitable society (or its opposite), depends from the relation established between ethical and governance options. A relation which intersects with political, financial and social development dimensions.

The literature review allowed us to conclude that personalization in education through the use of IoT is clearly possible and desirable. But, this will not be the best scenario until the AI-powered IoT mechanisms are fully optimized in what respects human development. The experts which were interviewed expressed a similar position. They've considered machine-assisted personalization of learning experiences to uphold great potential to improve the quality of education. However, profiling as an educational achievement based exclusively on IoT mechanisms powered by AI without ethics. The risks are high and real. Education can become too homogenous and deterministic. Consequently, learners face a real threat of being subject to constant monitoring. The misuse of the enormous amount of data generated jeopardizes several critical dimensions of their life experience (privacy, 
security and interaction) because of the potential capacity of automation to take control and decision. This threat however is not specific of education and learners. It represents a fundamental challenge of contemporary societies and individuals.

As a wonderful new world opens up at an unimaginable speed, promising us exciting new scenarios, this process is also takings by storm, leaving no time for reflection and to mature compromises. However, it's very important for the educational field, for all stakeholders involved, to reason about the impacts and consequences of this rapid and disruptive transformation. It is more urgent than ever important to think about technological design, cost and ownership. It is fundamental to think of personalization and commoditization as educational categories; to build a social and ethical matrix, as well as an ethical framework which will be able to guide institutions and inform quality practice.

\section{References}

Adams Becker, S., Freeman, A., Giesinger Hall, C., Cummins, M., \& Yuhnke, B. (2016). NMC Horizon Report: 2016 K-12 Edition. Austin, Texas: The New Media Consortium. Retrieved from http://cdn.nmc.org/media/2016-nmccosn-horizonreport-k12-EN.pdf

Adams Becker, S., Cummins, M., Davis, A., Freeman, A., Hall Giesinger, C., \& Ananthanarayanan, V. (2017). NMC Horizon Report: 2017 Higher Education Edition. Austin, Texas: The New Media Consortium. Retrieved from http://cdn.nmc.org/media/2017-nmc-horizon-report-he-EN.pdf

Alexander, B., Ashford-Rowe, K., Barajas-Murphy, N., Dobbin, G., Knott, J., McCormack, M., Pomerantz, J., Seilhamer, R. \& Weber, N. (2019). EDUCAUSE Horizon Report: 2019 Higher Education Edition. Louisville. CO: EDUCAUSE. Retrieved from https://library.educause.edu//media/files/library/2019/4/2019horizonreport.pdf?la=en\&hash=C8E8D444AF372E7 05FA1BF9D4FF0DD4CC6F0F DD1

Adams Becker, S., Brown, M., Dahlstrom, E., Davis, A., DePaul, K. Diaz, V., \& Pomerantz, J. (2018). NMC Horizon Report: 2018 Higher Education Edition. Louisville. CO: EDUCAUSE. Retrieved from https://library.educause.edu/ /media/files/library/2018/8/2018horizonreport.pdf

Brown, M., McCormack, M., Reeves, J., Brooks, D. C., Grajek, S., Alexander, B., Bali, M., Bulger, S., Dark, S., Engelbert, N., Gannon, K., Gauthier, A., Gibson, D., Gibson, R., Lundin, B., Veletsianos, G., \& Weber, N. (2020). 2020 EDUCAUSE Horizon Report, Teaching and Learning Edition. Louisville. CO: EDUCAUSE. Retrieved from https://library.educause.edu//media/files/library/2019/4/2019horizonreport.pdf?la=e $\mathrm{n} \&$ hash =C8E8D444AF372E705FA1BF9D4FF0DD4CC6F0F DD1 
Buchem, I., \& Pérez-Sanagustín, M. (2013). Personal learning environments in Smart Cities: Current Approaches and Future Scenarios. ELearning Papers, 35. Retrieved from https://www.openeducationeuropa.eu/sites/default/files/asset/Indepth_35_1_0.pdf

Freeman, A., Adams Becker, S., Cummins, M., McKelroy, E., Giesinger, C., \& Yuhnke, B. (2016). NMC Horizon Report: 2016 Museum Edition. Austin, Texas: The New Media Consortium. Retrieved from https://www.nmc.org/publication/nmc-horizon-report2016-museum-edition/

Johnson, L., Adams Becker, S., Cummins, M., Estrada, V., Freeman, A., \& Ludgate, H. (2013). NMC Horizon Report: Edição K12 2013.Tradução para o português pela Ez2translate. Austin, Texas: The New Media Consortium. Retrieved from https://edisciplinas.usp.br/pluginfile.php/2532254/mod_resource/content/1/2013hori zonreport-k12-PT.pdf

Johnson, L., Adams Becker, S., Estrada, V., \& Freeman, A. (2014). NMC Horizon Report: 2014 K-12 Edition. Austin, Texas: The New Media Consortium. Retrieved from http://cdn.nmc.org/media/2014-nmc-horizon-report-k12EN.pdf

Johnson, L., Adams Becker, S., Estrada, V., \& Freeman, A. (2015). NMC Horizon Report: 2015 Museum Edition. Austin, Texas: The New Media Consortium.

Meyers, M. (2015, March 28). Connecting the Classroom with the Internet of Things. EdSurge [Blog post]. Retrieved from https://www.edsurge.com/news/2015-03-28connecting-the-classroom-with-the-internet-ofthings

Advanced MP Technology Inc. (2013). The Future of IoTs in Education. Retrieved from http://www.advancedmp.com/thefuture-of-iots-in-education/

Perera, C., Zaslavsky, A., Christen, P., \& Georgakopoulos, D. (2013). Context Aware Computing for the Internet of Things: A Survey. IEEE Communications Surveys \& Tutorials conference, 16(1). Retrieved from https://ieeexplore.ieee.org/document/6512846 